\title{
Anaemia and depression before and after birth: a cohort study based on linked population data
}

\author{
Fenglian Xu ${ }^{1 *} \mathbb{D}$, Lynette Roberts ${ }^{2}$, Colin Binns ${ }^{3}$, Elizabeth Sullivan ${ }^{1}$ and Caroline S. E. Homer ${ }^{1}$
}

\begin{abstract}
Background: To investigate the rates of hospitalisation for anaemia and depression in women in the six-year period ( 3 years before and after birth). To compare hospital admissions for depression in women with and without anaemia.

Methods: This is a population-based cohort study. Women's birth records (New South Wales (NSW) Perinatal Data Collection) were linked with NSW Admitted Patients Data Collection records between 1 January 2001 and 31 December 2010, so that hospital admissions for mothers could be traced back for 3 years before birth and followed up 3 years after birth. Setting: NSW Australia. Subjects: all women who gave birth to their first child in NSW between 1 January 2004 and 31 December 2008.

Results: Hospital admissions for both anaemia and depression were increased significantly in the year just before and after birth compared with the years before and after. Women with anaemia were more likely to be admitted to hospital for depression than those without (for principal diagnosis of depression, adjusted $\mathrm{OR}=1.62$, $95 \% \mathrm{Cl}=1.25-2.11$; for all diagnosis of depression, adjusted $\mathrm{OR}=2.01,95 \% \mathrm{Cl}=1.70-2.38$ ).

Conclusions: Depression was associated with anaemia in women before and after birth. This finding highlight the important role of primary care providers in assessing for both anaemia and depressive symptomatology together, given the relationship between the two. Treating or preventing anaemia may help to prevent postnatal depression.
\end{abstract}

Keywords: Anaemia, Depression, Risk factors, Women, Birth

\section{Background}

Depression in the postnatal period is a major health problem [1-3], with adverse outcomes for the mother and baby [4] including bonding [5-8], child's later socioemotional development [9] academic achievement [10] and risk for psychopathologies [9]. One in every seven or eight women (around 12-16\%) will experience depressive symptoms in the post-partum period [11-14], costing the Australian economy $\$ 113.86$ million annually [13]. We have previously shown that the hospital admission rates for psychiatric disorders increased in the first year after birth significantly between 2001 and 2010 (1.16\% in 2001, 2.28\% in 2010) [15] in New South Wales (NSW) of Australia. The hospital admission increase

\footnotetext{
* Correspondence: Fenglian.Xu@uts.edu.au

${ }^{1}$ Faculty of Health, University of Technology Sydney, Ultimo 2007, Australia Full list of author information is available at the end of the article
}

was mainly attributed to unipolar depression, adjustment disorders and anxiety disorders [15].

Poor physical health is a risk factor for postnatal depression (PND). A prospective cohort study in1,507 nulliparous women in Melbourne of Australia showed that women with five or more physical health problems had a six-fold increase in the risk of depressive symptoms at 3 months postpartum and a three-fold increase in the risk of subsequent depressive symptoms at 6-12 months postpartum [14]. Women experiencing a greater number of physical health problems may be at an increased risk of postnatal depression.

One of these physical health risk factors is anaemia, a common problem for women (global prevalence of 29\%) [16], particularly in pregnancy (global prevalence of 38\%) [16] due to additional physiological demands on the mother. A population-based cross-sectional study of 
all singleton births $(n=511,938)$ in Finland between 2002 and 2010 reported that anaemia is a predictor of depression during pregnancy [17]. A prospective cohort study in Spain $(n=729)$ found that mothers with low levels of the iron marker, ferritin, at $48 \mathrm{~h}$ post-partum were 3.73 times more likely to have PND at 32 weeks [18]. Another prospective study in American women found that low concentrations of hemoglobin in mothers at 7 days postpartum correlated with depressive symptoms at 28 days postpartum [19]. However, a study in Chinese mothers found no association between iron levels in pregnancy and 3 days postpartum, with depression scores 24-48 h or 6 weeks after delivery [20].

Given the wide-reaching impact and costs on the individual, parent-child dyad and community, we sought to investigate whether there is an association between anaemia and depression in Australia. These findings could inform public health policy, including highlighting a potential link between preventable physical and mental health problems in the perinatal period. Specifically, we used population-based linked data in Australia to:

1. Describe the rates of hospitalization for anaemia and depression in mothers in the 3 years before and after giving birth.

2. Compare the association of hospital admission of depression in women with and without anaemia.

We hypothesized that anaemia is associated with an increase in hospital admissions for depression.

\section{Methods}

\section{Study population and design}

This is a population-based cohort study, including all women who gave birth to their first child in New South Wales (NSW) between 1 January 2004 and 31 December 2008. Mothers who had subsequent births in 4 years after the first birth were excluded. Data were linked using the NSW Perinatal Data Collection (PDC) and the NSW Admitted Patients Data Collection (APDC). Women's hospital admissions for anaemia and depressive disorders were identified by APDC records. Mother's birth records were linked with APDC records between 1 January 2001 and 31 December 2010, so that hospital admissions for mothers could be traced back for 3 years before birth and followed up 3 years after birth. The study population and data linkage are detailed in Figs. 1 and 2.

The PDC is a data collection of births of at least 20 weeks gestation or at least $400 \mathrm{~g}$ birthweight in NSW of Australia. It includes all births in hospitals (public and private) and home births. The database includes information on maternal characteristics and outcomes of pregnancy, labour and birth. The APDC is a routinely collected census of all hospital separations in NSW hospitals including public, private and psychiatric hospitals and day procedures. It covers all patient hospitalisations and includes information on patient demographics, diagnoses and clinical procedures. The diagnoses for admissions have been coded according to the 10th revision of the International Statistical Classification of Diseases and Related Health Problems, Australian Modification (ICD-10-AM) [21].

Data linkage was carried out by the NSW Department of Health Centre for Health Record Linkage (CHeReL). Each record from PDC and APDC datasets was assigned a Person Project Number to allow records for the same individual to be linked. In the 1000 randomly selected sample of records, the false positive rate of the linkage was $0.3 \%$ and false negative $<0.5 \%$.

\section{Diagnosis}

The diagnoses in each hospital admission record in APDC data include 55 diagnoses (one principal diagnosis, one stay diagnosis and 53 other diagnoses). Principal diagnosis refers to the one which was chiefly responsible for hospital admissions [22]. The stay diagnosis refers to the one that most influenced the length of stay in hospital [15]. Other diagnosis is an additional diagnosis. It refers to a condition or a complaint coexisting with the principal and stay diagnoses or arising during the hospitalisation [15]. Hospital admission refers to hospitalization (a patient was admitted to hospital for inpatient service). PND refers to the principal diagnoses of depression after birth. Anaemia refers to all diagnoses of anaemia (including principal and non-principal diagnoses). Mothers with anaemia were identified using ICD-10-AM diagnosis codes: (1) D50-D53 [nutritional anaemia]; (2) D55-D59 [haemolytic anaemia], (3) D60-D64 [aplastic and other anaemia] and O99.0 [anaemia complicating pregnancy, childbirth and the puerperium]. Mothers with depressive disorders were identified using ICD-10-AM diagnosis codes: (1) F32-F33 [depressive disorder] and (2) F53 [Mental and behavioural disorders associated with the puerperium]. Only the first hospital admission with the diagnosis of anaemia or depressive disorders was used for the analysis of the rate, odds ratio (OR) and adjusted OR.

\section{Statistics}

Descriptive statistics were used to summarise the rate and proportion of hospital admissions. The proportion was calculated by women's 1st hospital admissions for the diagnosis of anaemia or depression as nominator and overall hospital admissions as denominator. Logistic regression models were used to estimate the odds ratio (OR) of anaemia on hospitalisation for depression. The dependent variable is the first hospital admission for depression (yes/no) in the study period (3 years before birth and 3 years after the birth). The independent 


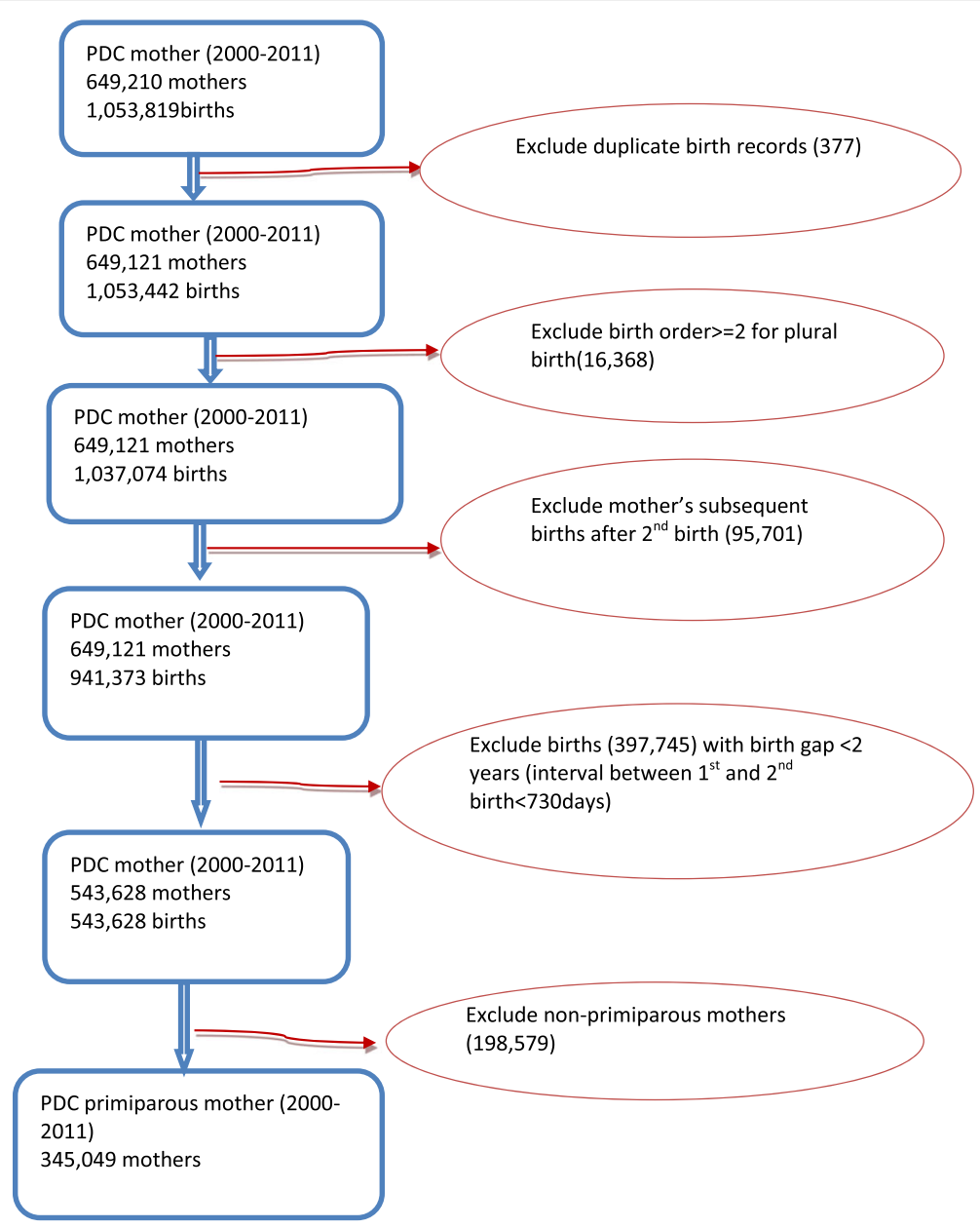

Fig. 1 The study population selection

variable is the first hospital admission for all diagnoses of anaemia in the study period. The adjusted factors for the OR include maternal age, maternal country of birth, maternal diabetes mellitus and hypertension, gestational diabetes, smoking status during pregnancy, remoteness of living area, method of birth, gestational age, baby's death and place of birth and the Index of Relative Socio-economic Disadvantage Quintile [23]. The analyses were conducted using IBM SPSS (Statistical Package for Social Science) Statistics 20.

\section{Results}

Characteristic of the study population and the rate of the first hospital admissions for anaemia are detailed in Table 1 . Young women $(<20$ years old) were more likely to be admitted to hospital with the diagnosis of anaemia than those aged between 25 and 39 years old. The mothers in disadvantaged group; with maternal diabetes mellitus or hypertension were also more likely to be admitted to hospitals with the diagnosis of anaemia. Mothers with anaemia were more likely to have stillbirth, preterm birth and their babies were more likely to die in neonatal/postnatal period.

There were 236 hospital admissions with principal diagnosis of anaemia and 2569 admissions with all diagnosis of anaemia in the study periods (3 years before birth and 3 years after birth) (Table 2). The admissions with principal diagnosis of anaemia only accounted for 9.19\% (236/2569) of the hospital admission for all anaemia diagnoses. That is, more than $90 \%$ anaemia was diagnosed as a non-principal diagnoses.

The rates of anaemia in women in the year just before and after giving birth were significantly higher than the 2 years before (the second and third year before birth) and 2 years after (the second and third year after birth) the period, especially for all diagnoses of anaemia (Table 2 and Fig. 3).The hospital admission rate for the principal diagnosis of anaemia was 0.83 per 1000 women $(95 \% \mathrm{CI}=0.63-1.03 / 1000)$ in the year just before birth; 0.93 per 1000 women $(95 \% \mathrm{CI}=0.71-1.15 / 1000)$ in the year just after birth. The hospital admission rate for all diagnosis of anaemia was 16.06 per 1000 


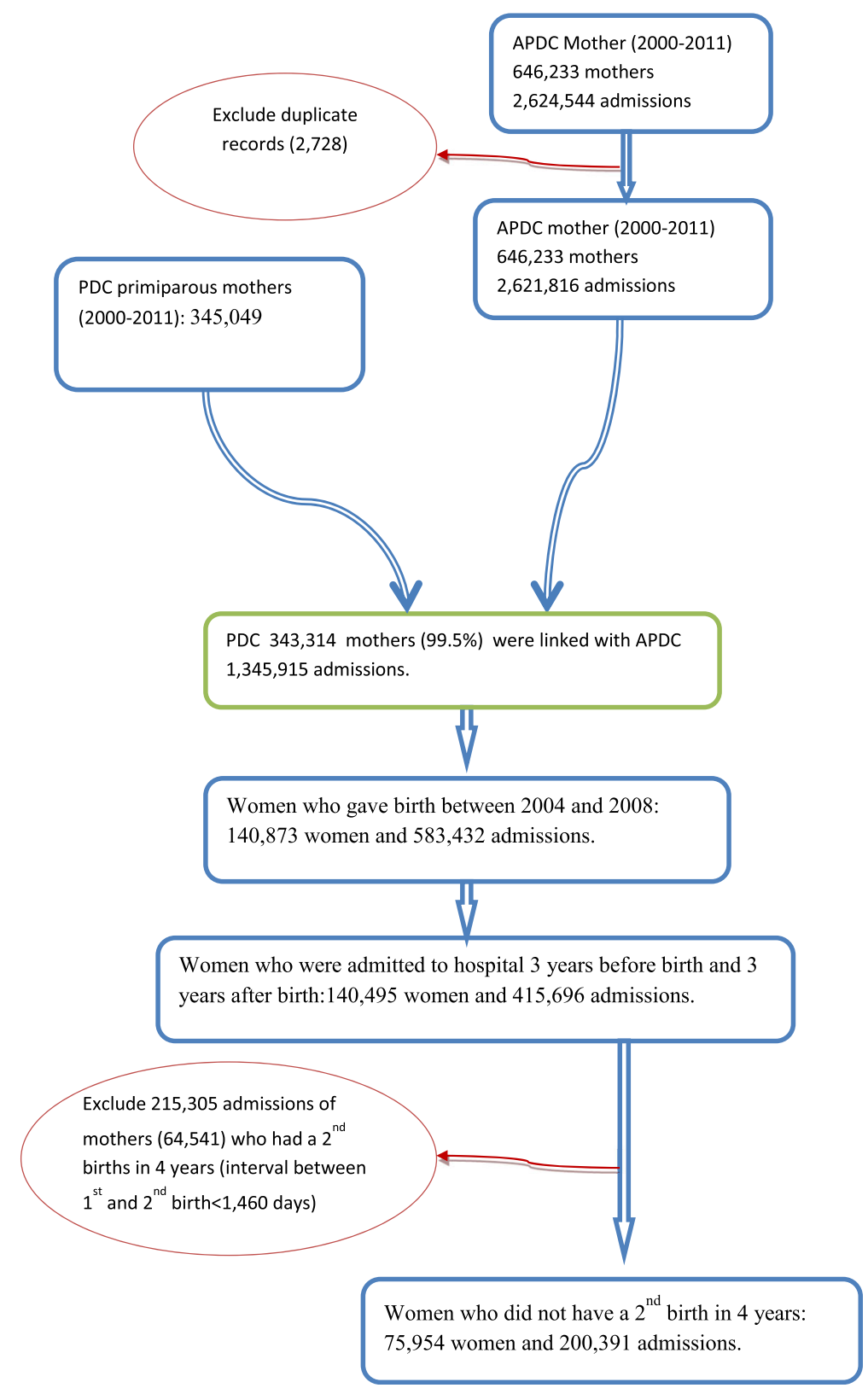

Fig. 2 The data linkage and study population

women $(95 \% \mathrm{CI}=15.17-16.95 / 1000)$ in the year just before the birth; 13.15 per 1000 women $(95 \% \mathrm{CI}=$ $12.34-13.96 / 1000$ ) in the year just after birth (Table 2).

The proportion of women's anaemia in the year just before and after birth were also significantly higher than the 2 years before (the second and third year before birth) and 2 years after (the second and third year after birth) this period for all diagnoses of anaemia (Table 3 and Fig. 3). For the principal diagnosis of anaemia, the proportion in the year just before the birth $(0.79 / 1000$ admission, $95 \% \mathrm{CI}=0.60-0.98)$ was lower than the third year before birth $(2.14 / 1000$ admission, $95 \% \mathrm{CI}=1.30-2.98)$ and the third year after birth(2.10/1000 admission, $95 \% \mathrm{CI}=$ 1.38-2.82); The proportion in the year just before the birth was not significantly different from the second year before birth and the first 2 years after birth.

Figure 4 shows that majority of the anaemia were attributed to anaemia complicating pregnancy, childbirth and the puerperium (38.71\% for principal diagnosis and $42.99 \%$ for all diagnosis) and nutritional anaemia (35.89\% for principal diagnosis and $15.47 \%$ for all diagnosis). Haemolytic anaemia accounted for $6.05 \%$ for principal diagnosis and $3.94 \%$ for all diagnosis of anaemia. Figure 4 also shows that there was more 
Table 1 Primiparous mother's characteristic and the 1st hospital admissions for anaemia 2001-2010, Australia

\begin{tabular}{|c|c|c|c|c|c|c|}
\hline Factor & Value & Mother & $\begin{array}{l}\text { Admission for } \\
\text { anaemia }\end{array}$ & Rate (\%) & $95 \%$ C & \\
\hline \multirow[t]{7}{*}{ Maternal age* } & $<20$ & 6284 & 262 & 4.17 & 3.68 & 4.66 \\
\hline & $20-24$ & 14,350 & 521 & 3.63 & 3.32 & 3.94 \\
\hline & $25-29$ & 19,833 & 662 & 3.34 & 3.09 & 3.59 \\
\hline & $30-34$ & 20,472 & 644 & 3.15 & 2.91 & 3.39 \\
\hline & $35-39$ & 11,479 & 364 & 3.17 & 2.85 & 3.49 \\
\hline & $40+$ & 3529 & 116 & 3.29 & 2.70 & 3.88 \\
\hline & Total & 75,947 & 2569 & 3.38 & 3.25 & 3.51 \\
\hline \multirow[t]{3}{*}{ Women's country of birth } & Australia & 48,331 & 1589 & 3.29 & 3.13 & 3.45 \\
\hline & Other countries & 27,623 & 980 & 3.55 & 3.33 & 3.77 \\
\hline & Total & 75,954 & 2569 & 3.38 & 3.25 & 3.51 \\
\hline \multirow[t]{4}{*}{ Remoteness* } & Major cities & 53,399 & 1827 & 3.42 & 3.27 & 3.57 \\
\hline & Inner regional & 16,092 & 497 & 3.09 & 2.82 & 3.36 \\
\hline & Out regional and remote & 5252 & 202 & 3.85 & 3.33 & 4.37 \\
\hline & Total & 74,743 & 2526 & 3.38 & 3.25 & 3.51 \\
\hline \multirow[t]{3}{*}{ Smoking during pregnancy } & No & 65,899 & 2224 & 3.37 & 3.23 & 3.51 \\
\hline & Yes & 9694 & 327 & 3.37 & 3.01 & 3.73 \\
\hline & Total & 75,593 & 2551 & 3.37 & 3.24 & 3.50 \\
\hline \multirow{6}{*}{$\begin{array}{l}\text { Index of Relative SE Disadvantage } \\
\text { Quintile* }\end{array}$} & 1st quintile least disadvantaged & 17,196 & 487 & 2.83 & 2.58 & 3.08 \\
\hline & 2.00 & 15,490 & 501 & 3.23 & 2.95 & 3.51 \\
\hline & 3.00 & 14,437 & 516 & 3.57 & 3.27 & 3.87 \\
\hline & 4.00 & 12,953 & 455 & 3.51 & 3.19 & 3.83 \\
\hline & 5th quintile most disadvantaged & 14,667 & 567 & 3.87 & 3.56 & 4.18 \\
\hline & Total & 74,743 & 2526 & 3.38 & 3.25 & 3.51 \\
\hline \multirow[t]{3}{*}{ Maternal diabetes mellitus* } & No & 75,488 & 2543 & 3.37 & 3.24 & 3.50 \\
\hline & Yes & 466 & 26 & 5.58 & 3.50 & 7.66 \\
\hline & Total & 75,954 & 2569 & 3.38 & 3.25 & 3.51 \\
\hline \multirow[t]{3}{*}{ Gestational diabetes } & No & 72,051 & 2417 & 3.35 & 3.22 & 3.48 \\
\hline & Yes & 3903 & 152 & 3.89 & 3.28 & 4.50 \\
\hline & Total & 75,954 & 2569 & 3.38 & 3.25 & 3.51 \\
\hline \multirow[t]{3}{*}{ Maternal hypertension* } & No & 75,175 & 2529 & 3.36 & 3.23 & 3.49 \\
\hline & Yes & 779 & 40 & 5.13 & 3.58 & 6.68 \\
\hline & Total & 75,954 & 2569 & 3.38 & 3.25 & 3.51 \\
\hline \multirow[t]{3}{*}{ Delivery mode } & Vaginal & 49,827 & 1641 & 3.29 & 3.13 & 3.45 \\
\hline & Caesarean section & 26,073 & 928 & 3.56 & 3.34 & 3.78 \\
\hline & Total & 75,900 & 2569 & 3.38 & 3.25 & 3.51 \\
\hline \multirow[t]{4}{*}{ Baby's death* } & None & 75,401 & 2526 & 3.35 & 3.22 & 3.48 \\
\hline & Still birth & 340 & 23 & 6.76 & 4.09 & 9.43 \\
\hline & Neonatal/post neonatal death & 151 & 16 & 10.60 & 5.69 & 15.51 \\
\hline & Total & 75,892 & 2565 & 3.38 & 3.25 & 3.51 \\
\hline \multirow[t]{4}{*}{ Gestational age (week)* } & $<28$ & 534 & 39 & 7.30 & 5.09 & 9.51 \\
\hline & $28-31$ & 696 & 50 & 7.18 & 5.26 & 9.10 \\
\hline & $32-36$ & 5153 & 221 & 4.29 & 3.74 & 4.84 \\
\hline & $37-41$ & 68,023 & 2189 & 3.22 & 3.09 & 3.35 \\
\hline
\end{tabular}


Table 1 Primiparous mother's characteristic and the 1st hospital admissions for anaemia 2001-2010, Australia (Continued)

\begin{tabular}{|c|c|c|c|c|c|c|}
\hline Factor & Value & Mother & $\begin{array}{l}\text { Admission for } \\
\text { anaemia }\end{array}$ & Rate (\%) & $95 \% \mathrm{Cl}$ & \\
\hline & $42 w+$ & 1540 & 70 & 4.55 & 3.51 & 5.59 \\
\hline & Total & 75,946 & 2569 & 3.38 & 3.25 & 3.51 \\
\hline \multirow[t]{4}{*}{ Place of birth* } & Hospital & 74,318 & 2512 & 3.38 & 3.25 & 3.51 \\
\hline & Birth Centre & 1482 & 46 & 3.10 & 2.22 & 3.98 \\
\hline & Others & 145 & 11 & 7.59 & 3.28 & 11.90 \\
\hline & Total & 75,945 & 2569 & 3.38 & 3.25 & 3.51 \\
\hline
\end{tabular}

SE Socioeconomic

*Significantly associated with the 1 st hospital admissions with anaemia by chi square test $(p<0.05)$

unspecified diagnosis of anaemia in non-principal diagnoses.

Table 4 shows the first hospital admissions for depression before and after birth. Compared with the hospital admissions before birth, the hospital admissions for depression increased significantly in the first and second year after birth. Women in the pregnancy year were less likely to be admitted to hospital compared with the 2 years before pregnancy and 3 years after birth. For principal diagnosis, the first hospital admission rate of depression was 8.94 per 1000 Person Year (PY) (95\% CI $=8.27-9.61)$ in the first year after birth; while the rate of depression was only $0.91 / 1000 \mathrm{PY}(95 \%$ $\mathrm{CI}=0.70-1.12)$ in the year before birth. For all diagnosis, the rate of depression was 16.02 per 1000 Person Year (PY) $(95 \% \mathrm{CI}=15.12-16.92)$ in the first year after birth; while the rate of depression was only 6.48/1000PY $(95 \% \mathrm{CI}=5.91-7.05)$ in the year before birth.

To consider the impact of the increase of overall hospital admissions during pregnancy and perinatal period, the proportion of depression was analysed (Table 5). Similar to the change of rate in Table 4, the proportion of hospital admissions for depression increased significantly in the first and second year after birth. Women's hospital admissions for depression in the year just before birth were the lowest compared with the 2 years before and 3 years after (Table 5 and Fig. 5).
Figure 5 shows that the difference of the proportion and rate of depression for both principal and all diagnosis. The proportions of depression (including both principal and all diagnosis) decreased significantly in the first year before birth compared with the rates of depression.

Table 6 shows the association between anaemia and depression in women. Women with anaemia were more likely to be admitted to hospital for depression (for principal diagnosis of depression, adjusted $\mathrm{OR}=1.62$, $95 \% \mathrm{CI}=1.25-2.11$ ) (for all diagnosis of depression, adjusted $\mathrm{OR}=2.01,95 \% \mathrm{CI}=1.70-2.38)$ than women without anaemia.

\section{Discussion}

This study showed that the hospital admissions for depression increased significantly in the first year after birth compared with those before birth. The increased trend after birth is consistent with our previous study [15] and other studies from other areas [24]. For depression, the proportions (including both principal and all diagnosis) decreased significantly in the year before birth because of the increase of overall hospital admissions.

This study also showed that hospital admissions for anaemia with all diagnosis were significantly increased in the year of pregnancy (16.06 per 1000 women, 95\% $\mathrm{CI}=15.17-16.95 / 1000)$ and the first year after birth (13.15 per 1000 women, $95 \% \mathrm{CI}=12.34-13.96 / 1000)$.

Table 2 The rate of women's 1st hospital admissions with the diagnosis of anaemia before and after birth $(n=75,954) 2001-2010$,

Australia

\begin{tabular}{|c|c|c|c|c|c|c|c|c|c|}
\hline \multicolumn{2}{|l|}{ Period } & \multirow{2}{*}{$\begin{array}{l}\text { Principal diagnosis } \\
25\end{array}$} & \multirow{2}{*}{$\begin{array}{l}\text { Rate }(/ 1000) \\
0.33\end{array}$} & \multicolumn{2}{|c|}{$95 \% \mathrm{Cl}$} & \multirow{2}{*}{$\begin{array}{l}\text { All diagnosis } \\
77\end{array}$} & \multirow{2}{*}{$\begin{array}{l}\text { Rate (/1000) } \\
1.01\end{array}$} & \multicolumn{2}{|c|}{$95 \% \mathrm{Cl}$} \\
\hline Before birth & $3 r d$ year & & & 0.2 & 0.46 & & & 0.78 & 1.24 \\
\hline & 2nd year & 21 & 0.28 & 0.16 & 0.4 & 88 & 1.16 & 0.92 & 1.4 \\
\hline & 1st year & 63 & 0.83 & 0.63 & 1.03 & 1220 & 16.06 & 15.17 & 16.95 \\
\hline \multirow[t]{3}{*}{ After birth } & 1st year & 71 & 0.93 & 0.71 & 1.15 & 999 & 13.15 & 12.34 & 13.96 \\
\hline & 2nd year & 23 & 0.30 & 0.18 & 0.42 & 88 & 1.16 & 0.92 & 1.4 \\
\hline & 3rd year & 33 & 0.43 & 0.28 & 0.58 & 97 & 1.28 & 1.03 & 1.53 \\
\hline Total & & 236 & 3.11 & 2.71 & 3.51 & 2569 & 33.82 & 32.53 & 35.11 \\
\hline
\end{tabular}




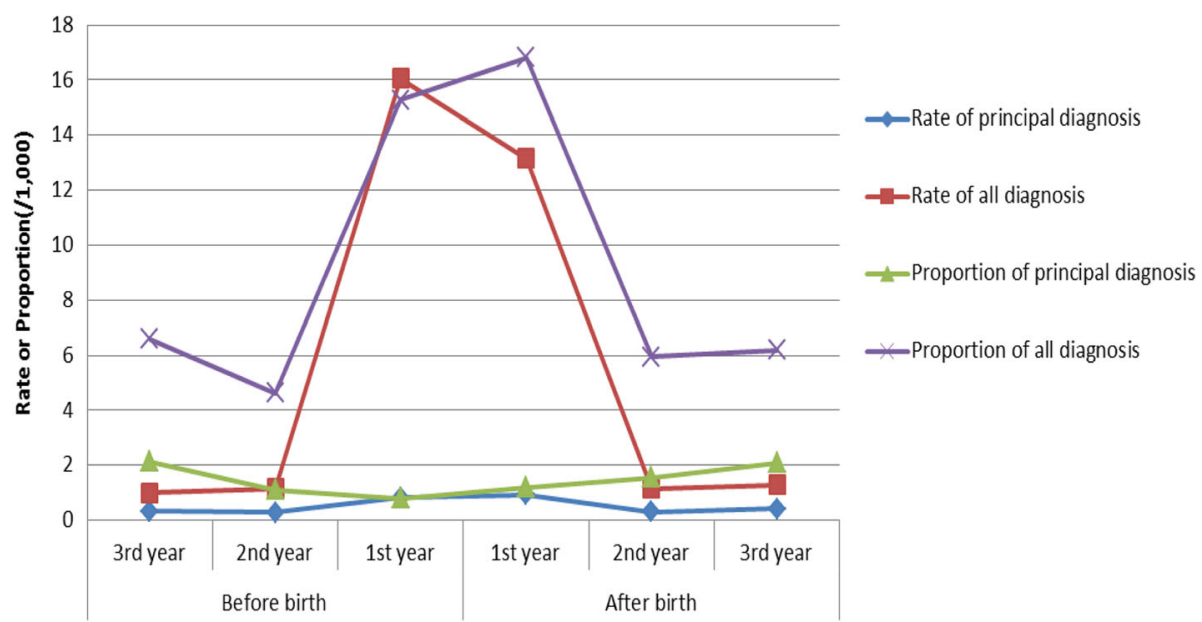

Fig. 3 The rate and proportion of women's hospital admissions for anaemia 2001-2010, Australia

To consider the impact of increased overall hospital admissions before and after birth, the proportion of anaemia was also analyzed. Similar to the hospital admission rate, the proportion of anaemia was also significantly increased in the year of pregnancy and the first after birth. A systematic analysis of population-representative data from 107 countries between 1995 and 2011 showed that global anaemia prevalence was between $29 \%$ (95\% credibility intervals $(\mathrm{CI})=24-35)$ and $33 \%(95 \% \mathrm{CI}=29-37)$ in non-pregnant women, $38 \%(95 \% \mathrm{CI}=34-43)$ and $43 \%$ $(95 \% \mathrm{CI}=39-47)$ in pregnant women [16]. In high-income regions (including Australia), anaemia prevalence was between $14 \%(95 \% \mathrm{CI}=12-18)$ and $16 \%$ (95\% CI $=12-22)$ in non-pregnant women, $22 \%(95 \% \mathrm{CI}=16-$ $29)$ and $23 \%(95 \% \mathrm{CI}=18-30)$ in pregnant women [16]. The rate of anaemia in NSW women was significantly lower than other areas [16]. This study imply that majority of women with Anaemia were not admitted to hospitals.

Majority of anaemia (91\%) was diagnosed as a nonprincipal diagnosis rather than principal diagnosis, as many women with anaemia were not diagnosed until they were admitted into hospital to give birth or for other medical reasons. Thus the greater the number of hospital admissions for other principal diagnoses, the greater the number of anaemia cases that will be found as an additional diagnosis. In New South Wales, 99.5\% women gave birth in hospitals, this provided a good opportunity to identify women with anaemia. To adjust the impact of overall hospital admissions, the proportion of hospital admissions for anaemia (overall hospital admissions as denominator) was calculated.

Women in the pre- and postnatal periods are particularly vulnerable to the effects of iron deficiency on mood through both direct and indirect pathways [25]. Factors such as peripartum blood losses, postpartum haemorrhaging, increased nutritional demands to support fetal developmental and breastfeeding, may cause iron-deficiency $[25,26]$, which may disrupt the functioning of neurotransmitters which implicated in mood.

This study showed that women with anaemia were more likely to be admitted to hospital for depression than those without. The finding are consistent with the results based on population-based cohort studies from Finland [17] and Spain [18]. Correspondingly, we see an association between iron-deficiency and mood across a

Table 3 The proportion of women's 1st hospital admissions with the diagnosis of anaemia in all hospital admissions 2001-2010,

Australia

\begin{tabular}{|c|c|c|c|c|c|c|c|c|c|c|}
\hline \multicolumn{2}{|l|}{ Period } & \multirow{2}{*}{$\begin{array}{l}\text { Hospital admissions } \\
11,671\end{array}$} & \multirow{2}{*}{$\begin{array}{l}\text { Principal diagnosis } \\
25\end{array}$} & \multirow{2}{*}{$\begin{array}{l}\text { Proportion (/1000) } \\
2.14\end{array}$} & \multicolumn{2}{|c|}{$95 \% \mathrm{Cl}$} & \multirow{2}{*}{$\begin{array}{l}\text { All diagnosis } \\
77\end{array}$} & \multirow{2}{*}{$\begin{array}{l}\text { Proportion (/1000) } \\
6.6\end{array}$} & \multicolumn{2}{|c|}{$95 \% \mathrm{Cl}$} \\
\hline Before birth & $3 r d$ year & & & & 1.30 & 2.98 & & & 5.13 & 8.07 \\
\hline & 2nd year & 18,965 & 21 & 1.11 & 0.64 & 1.58 & 88 & 4.64 & 3.67 & 5.61 \\
\hline & 1st year & 79,903 & 63 & 0.79 & 0.60 & 0.98 & 1220 & 15.27 & 14.42 & 16.12 \\
\hline \multirow[t]{3}{*}{ After birth } & 1st year & 59,383 & 71 & 1.2 & 0.92 & 1.48 & 999 & 16.82 & 15.79 & 17.85 \\
\hline & 2nd year & 14,790 & 23 & 1.56 & 0.92 & 2.20 & 88 & 5.95 & 4.71 & 7.19 \\
\hline & 3rd year & 15,679 & 33 & 2.1 & 1.38 & 2.82 & 97 & 6.19 & 4.96 & 7.42 \\
\hline Total & & 200,391 & 236 & 1.18 & 1.03 & 1.33 & 2569 & 12.82 & 12.33 & 13.31 \\
\hline
\end{tabular}




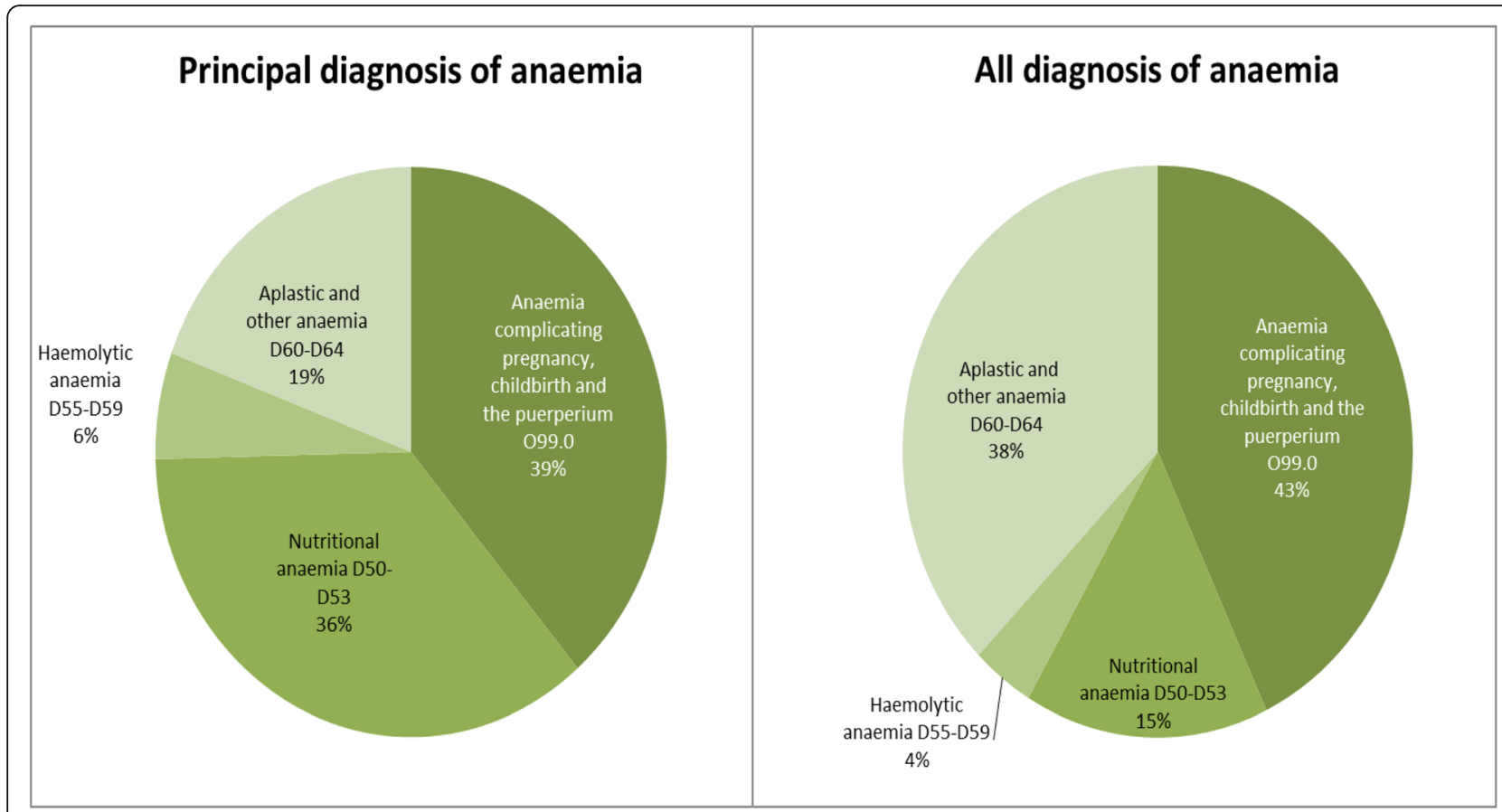

Fig. 4 The percentage of diagnoses of anaemia for women's hospital admissions before and after birth 2001-2010, Australia

range of studies, such as high rates of anaemia in psychiatric patients with chronic depression [2], and conversely, higher rates of depression in people with anaemia [1, 27]. Lever-van Milligen and colleagues found that anaemia status was associated with depression [28].

Potential mechanisms of effect for the relationship between anaemia and depression may associated with the role of iron in mood regulation. Iron contributes to myelination in the brain, as well as the development and functioning of the monamine system, which are key neurotransmitters involved in mood such as serotonin, dopamine and noradrenaline [29, 30]. Iron deficiency alters the signalling, production and metabolism of these monamines, including other key excitatory and inhibitory neurotransmitters such as glutamate and $\gamma$-aminobutyric acid respectively, which govern brain activity [29]. Imbalances in the concentration of these neurotransmitters then affect emotion regulation leading to depressed mood and behaviour [31-33]. Research with iron-deficient mothers in Africa found that iron supplementation successfully treated mood and cognitive disturbances [34].

In addition to this proposed direct pathway, iron deficiency and depression may be associated via an indirect, stress-induced inflammatory pathway. The individuals with depression experience chronic psychosocial and physical stressors. The stress lead to an overactive hypothalamic-pituitary-adrenal (HPA) axis, which triggers stress-induced elevated levels of pro-inflammatory cytokines [35-38]. Pro-inflammatory cytokines interfere with the functioning of monamines, resulting in a reduction of available neurotrasmitters [39-42]. This inflammatory response also affects iron metabolism, with depressed patients showing reduced hemoglobin $(\mathrm{Hb})$ levels and red blood cell count relative to controls [43, 44].

Table 4 The 1st Hospital admissions for depressive disorders in 3 years before and after birth 2001-2010, Australia

\begin{tabular}{|c|c|c|c|c|c|c|c|c|c|c|c|}
\hline \multicolumn{2}{|l|}{ Period } & \multirow{2}{*}{$\begin{array}{l}\text { Mothers (PY) } \\
75,954\end{array}$} & \multirow{2}{*}{$\begin{array}{l}\text { Principal diagnosis } \\
96\end{array}$} & \multirow{2}{*}{$\begin{array}{l}\text { Rate (/1000PY) } \\
1.26\end{array}$} & \multicolumn{2}{|c|}{$95 \% \mathrm{Cl}$} & \multirow{2}{*}{$\begin{array}{l}\text { Mothers (PY) } \\
75,954\end{array}$} & \multirow{2}{*}{$\begin{array}{l}\text { All diagnosis } \\
229\end{array}$} & \multirow{2}{*}{$\begin{array}{l}\text { Rate (/1000PY) } \\
3.01\end{array}$} & \multicolumn{2}{|c|}{$95 \% \mathrm{Cl}$} \\
\hline Before birth & $3 r d$ year & & & & 1.01 & 1.51 & & & & 2.62 & 3.4 \\
\hline & 2nd year & 75,858 & 85 & 1.12 & 0.88 & 1.36 & 75,725 & 207 & 2.73 & 2.36 & 3.10 \\
\hline & 1st year & 75,773 & 69 & 0.91 & 0.70 & 1.12 & 75,518 & 489 & 6.48 & 5.91 & 7.05 \\
\hline \multirow[t]{3}{*}{ After birth } & 1st year & 75,704 & 677 & 8.94 & 8.27 & 9.61 & 75,029 & 1202 & 16.02 & 15.12 & 16.92 \\
\hline & 2nd year & 75,027 & 158 & 2.11 & 1.78 & 2.44 & 73,827 & 226 & 3.06 & 2.66 & 3.46 \\
\hline & $3 r d$ year & 74,869 & 85 & 1.14 & 0.90 & 1.38 & 73,601 & 121 & 1.64 & 1.35 & 1.93 \\
\hline Total & & 453,185 & 1170 & 2.58 & 2.43 & 2.73 & 449,654 & 2474 & 5.50 & 5.28 & 5.72 \\
\hline
\end{tabular}

PY Refers to person year, Cl Refers to confidence interval 
Table 5 The proportion of women's 1st hospital admissions with the diagnosis of depression in all hospital admissions 2001-2010, Australia

\begin{tabular}{|c|c|c|c|c|c|c|c|c|c|c|}
\hline \multicolumn{2}{|l|}{ Period } & \multirow{2}{*}{$\begin{array}{l}\text { Hospital admissions } \\
11,671\end{array}$} & \multirow{2}{*}{$\begin{array}{l}\text { Principal diagnosis } \\
96\end{array}$} & \multirow{2}{*}{$\frac{\text { Rate (/1000PY) }}{8.23}$} & \multicolumn{2}{|c|}{$95 \% \mathrm{Cl}$} & \multirow{2}{*}{$\begin{array}{l}\text { All diagnosis } \\
229\end{array}$} & \multirow{2}{*}{$\frac{\text { Rate (/1000PY) }}{19.62}$} & \multicolumn{2}{|l|}{$95 \% \mathrm{Cl}$} \\
\hline Before birth & $3 r d$ year & & & & 6.59 & 9.87 & & & 17.1 & 22.14 \\
\hline & 2nd year & 18,965 & 85 & 4.48 & 3.53 & 5.43 & 207 & 10.91 & 9.43 & 12.39 \\
\hline & 1st year & 79,903 & 69 & 0.86 & 0.66 & 1.06 & 489 & 6.12 & 5.58 & 6.66 \\
\hline \multirow[t]{4}{*}{ After birth } & 1 st year & 59,383 & 677 & 11.40 & 10.55 & 12.25 & 1202 & 20.24 & 19.11 & 21.37 \\
\hline & 2nd year & 14,790 & 158 & 10.68 & 9.02 & 12.34 & 226 & 15.28 & 13.3 & 17.26 \\
\hline & $3 r d$ year & 15,679 & 85 & 5.42 & 4.27 & 6.57 & 121 & 7.72 & 6.35 & 9.09 \\
\hline & Total & 200,391 & 1170 & 5.84 & 5.51 & 6.17 & 2474 & 12.35 & 11.87 & 12.83 \\
\hline
\end{tabular}

\section{Strengths and limitations}

The strengths of this study include the population-based methodology, and data spanning a 6 year period to offer a richer understanding of mental and physical health in Australian women. Our findings present a baseline period from which to monitor the association between anaemia and depression in Australian women.

These findings also need to be considered within the context of study limitations.

This study shows that, for the principal diagnosis of anaemia, the proportion in the year just before the birth was lower than the third year before birth and the third year after birth. This was because women's hospital admissions increased significantly in the pregnancy year (more than four times than the second and third year before birth and the second and third years after birth), however the absolute hospital admissions were still higher than the 2 years before and the 2 years after the year of birth. This study further showed that the proportion of depression for both principal and all diagnosis decreased significantly in the first year before birth (Fig. 5). This was because of the increase of women's hospital admission in the year of pregnancy. The rates of depression for both principal and all diagnosis were less likely to be impacted by the number of overall admissions because the denominator for the rate analysis was the number of women rather than admissions. For anaemia, the proportion did not decrease as significantly as depression because the number of hospital admissions with the diagnoses of anaemia also increased significantly in the year of pregnancy (Fig. 3).

The 'other anaemia' diagnosis included the cases without clear diagnosis such as unspecified anaemia. As a result, the diagnosis for D60-D64 (aplastic and other anaemia) included relatively more cases. For women before and after birth, unspecified common anaemia such as anaemia complicating pregnancy, childbirth and the puerperium (O99.0) may be included in this group.

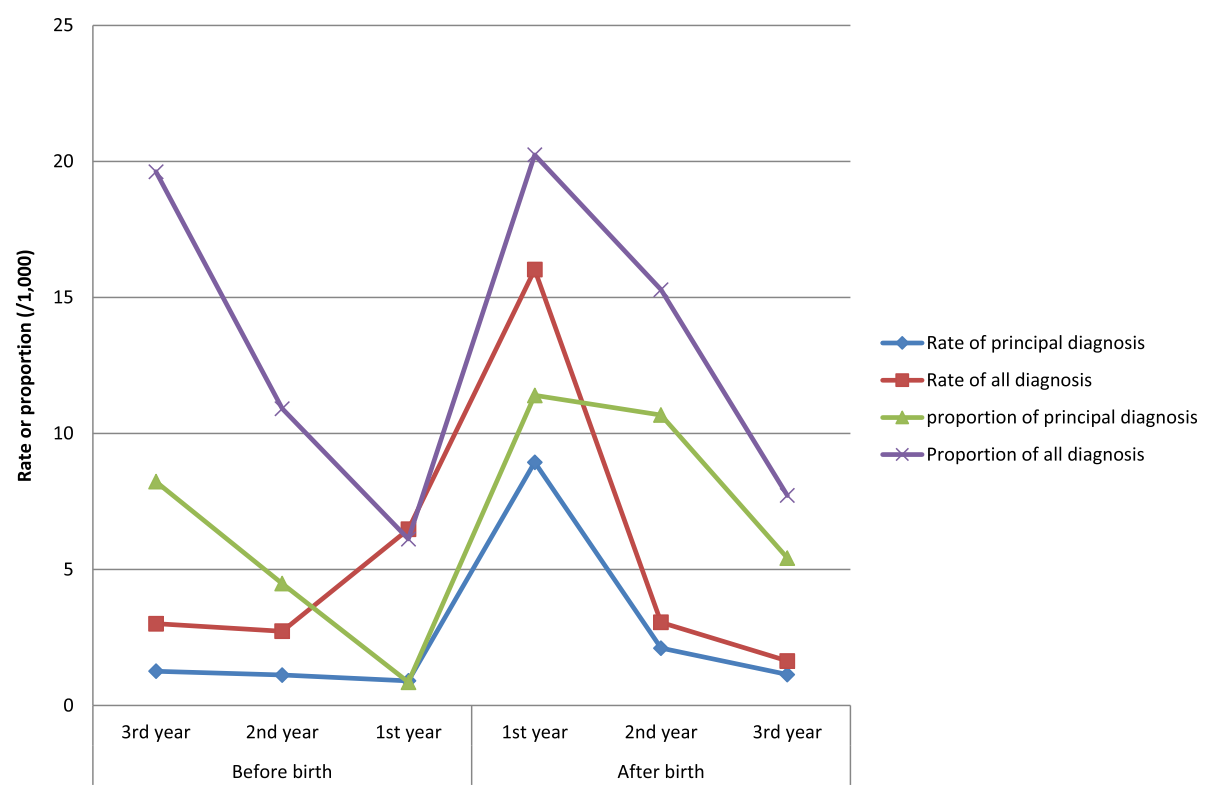

Fig. 5 The rate and proportion of women's hospital admissions for depression 2001-2010, Australia 
Table 6 The odds ratios (OR) of hospital admissions for depressive disorders in women with and without anaemia 2001-2010, Australia

\begin{tabular}{|c|c|c|c|c|c|c|c|c|c|c|}
\hline Diagnoses of depression & $\begin{array}{l}\text { Hospital admissions } \\
\text { for anaemia }\end{array}$ & N & $\begin{array}{l}\text { Hospital admissions } \\
\text { for depression }\end{array}$ & Rate (\%) & Crude OR & $95 \%$ C & & Adjusted OR & $95 \%$ C & \\
\hline \multirow[t]{3}{*}{ Principal diagnosis } & No & 73,385 & 1109 & 1.51 & 1 & & & 1 & & \\
\hline & Yes & 2569 & 61 & 2.37 & 1.59 & 1.22 & 2.06 & 1.62 & 1.25 & 2.11 \\
\hline & Total & 75,954 & 1170 & 1.54 & & & & & & \\
\hline \multirow[t]{3}{*}{ All diagnosis } & No & 73,385 & 2317 & 3.16 & 1 & & & 1 & & \\
\hline & Yes & 2569 & 157 & 6.11 & 2.00 & 1.69 & 2.36 & 2.01 & 1.70 & 2.38 \\
\hline & Total & 75,954 & 2474 & 3.26 & & & & & & \\
\hline
\end{tabular}

The adjusted OR was adjusted for maternal age, maternal country of birth, maternal diabetes mellitus and hypertension, gestational diabetes, smoking status during pregnancy, remoteness of living area, delivery method, gestational age, baby's death, place of birth and a socioeconomic indicator (i.e. the Index of Relative Socio-economic Disadvantage Quintile)

Some researchers mentioned that hospital admissions for PND might be over-enumerated because hospital admission could occur for other medical reasons in the postnatal period $[45,46]$. Furthermore, there was discussion over whether PND is a specific disorder distinct from major depressive disorder $[47,48]$ and maternal fatigue [49]. To minimise the potential overestimation of the rates, we only included the admissions with a 'principal' diagnosis of depressive disorders. On the other hand, the PND rates reported here might be under-estimated rather than over-estimated because hospital admissions would most likely reflect severe cases of PND [50] and majority of women experiencing PND were undetected and un-referred for mental health treatment by their obstetrical providers [51].

Temporal order between anaemia and depression could not be investigated by this study because majority of anaemia were diagnosed later than its occurrence. Majority of anaemia did not be found until women were admitted to hospital for giving birth or other reasons.

\section{Public health recommendations}

This is the first population-based study to demonstrate a possible link between anaemia and depression in Australia, and emphasizes the importance and inter-relationship of both mental and physical health in the period before and after birth. Current clinical care practice guidelines recommend psychoeducation on the importance of iron during pregnancy and iron screening for women at risk of anaemia [52], as well as routine screening and monitoring of depressive symptoms [53]. Our findings highlight the important role of primary care providers in assessing for both anaemia and depressive symptomatology together, given the relationship between the two. Knowledge of the psychiatric implications of iron status in the postnatal period is critical given that approximately one-fifth of Australian women are already iron-deficient at the start of pregnancy [54], and PND can also be chronic for a subgroup of women [55].

\section{Conclusion}

Anaemia was associated with postnatal depression for women. This finding highlight the important role of primary care providers in assessing for both anaemia and depressive symptomatology together, given the relationship between the two. Treating or preventing anaemia may help to prevent postnatal depression.

\section{Abbreviations}

ABS: Australian Bureau of Statistics; ACPCP: Anaemia complicating pregnancy, childbirth and the puerperium 099.0; APDC: Admitted patients data collection; CHeReL: Centre for Health Record Linkage; Cl: Confidence interval; HPA: Hypothalamic-pituitary-adrenal axis; MDC: Midwives data collection; NHMRC: The National Health and Medical Research Council; NSW: New South Wales; PDD: Postnatal depressive disorders; PND: Postnatal depression; SNOMED CT: Systematized Nomenclature of Medicine - Clinical Terms

\section{Acknowledgements}

We would like to thank data custodians of the Ministry of Health and staff of the Centre for Health Record Linkage (CheReL) for providing the data, providing advice and undertaking data linkage. We acknowledge the families who have contributed their data and professional staff involved in the data collection and management for this study.

\section{Funding}

Funding for this study was provided by Chancellor's Postdoctoral Research Fellowship of University of Technology Sydney. 2015-2018.

\section{Availability of data and materials}

The data that support the findings of this study are available from NSW Department of Health Centre for Health Record Linkage (CHeReL) but restrictions apply to the availability of these data, which were used under license for the current study, and so are not publicly available. Data are however available from the authors upon reasonable request and with permission of data custodians of the NSW Ministry of Health and CheReL.

\section{Authors' contributions}

FX analyzed the data, interpreted the results and was involved in manuscript writing. LR contributed to manuscript writing. $\mathrm{CH}, \mathrm{CB}$ and $\mathrm{ES}$ have revised the manuscript. All authors participated in the study design and interpretation of data. All authors read and approved the final manuscript.

\section{Ethics approval and consent to participate}

This study was approved by the NSW Population and Health Services Research Ethics Committee and the Human Research Ethics Committee of the University of New South Wales (HREC/11ICIPHS/33) and University of Technology Sydney, Australia. This study is based on de-identified existing data and participant consent is unnecessary. 


\section{Competing interests}

The authors declare that they have no competing interests.

\section{Publisher's Note}

Springer Nature remains neutral with regard to jurisdictional claims in published maps and institutional affiliations.

\section{Author details}

${ }^{1}$ Faculty of Health, University of Technology Sydney, Ultimo 2007, Australia. 2Discipline of Clinical Psychology, Graduate School of Health, University of Technology Sydney, Ultimo 2007, Australia. ${ }^{3}$ School of Public Health, Curtin University, Perth, Australia.

Received: 2 January 2018 Accepted: 20 June 2018

Published online: 13 July 2018

\section{References}

1. Chen M-H, Su T-P, Chen Y-S, Hsu J-W, Huang K-L, Chang W-H, Chen T-J, Bai Y-M. Association between psychiatric disorders and iron deficiency anemia among children and adolescents: a nationwide population-based study. BMC Psychiatry. 2013;13(1):161.

2. Korkmaz S, Yıldız S, Korucu T, Gundogan B, Sunbul ZE, Korkmaz H, Atmaca M. Frequency of anemia in chronic psychiatry patients. Neuropsychiatr Dis Treat. 2015;11:2737.

3. World Health Organization. Mental health aspects of women's reproductive health : a global review of the literature. Geneva: WHO Library Cataloguingin-Publication Data; 2009.

4. Dunkel Schetter C, Tanner L. Anxiety, depression and stress in pregnancy: implications for mothers, children, research, and practice. Curr Opin Psychiatry. 2012;25(2):141-8.

5. Muzik M, Bocknek E, Broderick A, Richardson P, Rosenblum K, Thelen K, Seng J. Mother-infant bonding impairment across the first 6 months postpartum: the primacy of psychopathology in women with childhood abuse and neglect histories. Arch Womens Ment Health. 2013;16(1):29-38.

6. O'Higgins M, Roberts I, Glover V, Taylor A. Mother-child bonding at 1 year; associations with symptoms of postnatal depression and bonding in the first few weeks. Arch Womens Ment Health. 2013;16(5):381-9.

7. Beestin L, Hugh-Jones S, Gough B. The impact of maternal postnata depression on men and their ways of fathering: an interpretative phenomenological analysis. Psychol Health. 2014;29(6):717-35.

8. Letourneau NL, Dennis C-L, Benzies K, Duffett-Leger L, Stewart M, Tryphonopoulos PD, Este D, Watson W. Postpartum depression is a family affair: addressing the impact on mothers, fathers, and children. Issues Ment Health Nurs. 2012:33(7):445-57.

9. Apter-Levy Y, Feldman M, Vakart A, Ebstein RP, Feldman R. Impact of maternal depression across the first 6 years of life on the Child's mental health, social engagement, and empathy: the moderating role of oxytocin. Am J Psychiatr. 2013;170(10):1161-8.

10. Pearson RM, Bornstein MH, Cordero M, Scerif G, Mahedy L, Evans J, Abioye A, Stein A. Maternal perinatal mental health and offspring academic achievement at age 16: the mediating role of childhood executive function. J Child Psychol Psychiatry. 2016;57(4):491-501.

11. Buist AE, Austin M-PV, Hayes BA, Speelman C, Bilszta JL, Gemmill AW, Brooks J, Ellwood D, Milgrom J. Postnatal mental health of women giving birth in Australia 2002-2004: findings from the beyondblue National Postnatal Depression Program. Aust N Z J Psychiatry. 2008;42(1):66-73.

12. Eastwood JG, Phung H, Barnett B. Postnatal depression and sociodemographic risk: factors associated with Edinburgh depression scale scores in a metropolitan area of new South Wales, Australia. Aust N Z J Psychiatry. 2011;45(12):1040-6.

13. PANDA. The cost of perinatal depression in Australia: final report - post and antenatal depression association. Sydney Avenue: Deloitte Access Economics; 2012.

14. Woolhouse H, Gartland D, Perlen S, Donath S, Brown SJ. Physical health after childbirth and maternal depression in the first 12 months post partum: results of an Australian nulliparous pregnancy cohort study. Midwifery. 2014; 30(3):378-84.

15. Xu F, Sullivan EA, Li Z, Burns L, Austin MP, Slade T. The increased trend in mothers' hospital admissions for psychiatric disorders in the first year after birth between 2001 and 2010 in new South Wales, Australia. BMC Womens Health. 2014;14:119.
16. Stevens GA, Finucane MM, De-Regil LM, Paciorek CJ, Flaxman SR, Branca F, Peña-Rosas JP, Bhutta ZA, Ezzati M. Global, regional, and national trends in haemoglobin concentration and prevalence of total and severe anaemia in children and pregnant and non-pregnant women for 1995-2011: a systematic analysis of population-representative data. Lancet Glob Health. 2013;1(1):e16-e25

17. Räisänen S, Lehto SM, Nielsen HS, Gissler M, Kramer MR, Heinonen S. Risk factors for and perinatal outcomes of major depression during pregnancy: a population-based analysis during 2002-2010 in Finland. BMJ Open. 2014; 4(11):e004883.

18. Albacar G, Sans T, Martín-Santos R, García-Esteve L, Guillamat R, Sanjuan J, Cañellas F, Gratacòs M, Cavalle P, Arija V. An association between plasma ferritin concentrations measured $48 \mathrm{~h}$ after delivery and postpartum depression. J Affect Disord. 2011;131(1):136-42.

19. Corwin EJ, Murray-Kolb LE, Beard JL. Low hemoglobin level is a risk factor for postpartum depression. J Nutr. 2003;133(12):4139-42.

20. Armony-Sivan R, Shao J, Li M, Zhao G, Zhao Z, Xu G, Zhou M, Zhan J, Bian $Y$, Ji C. No relationship between maternal iron status and postpartum depression in two samples in China. J Pregnancy. 2012:2012:521431.

21. National Centre for Classification in Health. The international statistical classification of diseases and related health problems, 10th revision, Australian modification (ICD-10-AM). Sydney: National Centre for Classification in Health; 1999.

22. Australian Institute of Health and Welfare. Australian hospital statistics 200809. Health services series no. 17. Cat. no. HSE 84. Canberra: AlHW; 2010.

23. Adhikari P. Socio-economic indexes for areas: introduction, use and future directions, vol. 1351.0.55.015. Canberra: Australian Bureau of Statistics; 2006.

24. Almond P. Postnatal depression: a global public health perspective. Perspect Public Health. 2009;129(5):221-7.

25. Milman N. Postpartum anemia I: definition, prevalence, causes, and consequences. Ann Hematol. 2011;90(11):1247-53.

26. Miller JL. Iron deficiency Anemia: a common and curable disease. Cold Spring Harb Perspect Med. 2013;3(7):a011866.

27. Shariatpanaahi MV, Shariatpanaahi ZV, Moshtaaghi M, Shahbaazi S, Abadi A The relationship between depression and serum ferritin level. Eur J Clin Nutr. 2007:61(4):532-5.

28. Lever-van Milligen BA, Vogelzangs N, Smit JH, Penninx BW. Hemoglobin levels in persons with depressive and/or anxiety disorders. J Psychosom Res. 2014;76(4):317-21.

29. Kim J, Wessling-Resnick M. Iron and mechanisms of emotional behavior. J Nutr Biochem. 2014;25(11):1101-7.

30. Beard JL, Connor JR. Iron status and neural functioning. Annu Rev Nutr. 2003:23(1):41-58.

31. Willner P, Scheel-Krüger J, Belzung C. The neurobiology of depression and antidepressant action. Neurosci Biobehav Rev. 2013;37(10, Part 1):2331-71.

32. Haase J, Brown E. Integrating the monoamine, neurotrophin and cytokine hypotheses of depression - a central role for the serotonin transporter? Pharmacol Ther. 2015;147:1-11

33. Krishnan $\mathrm{V}$, Nestler EJ. The molecular neurobiology of depression. Nature. 2008;455(7215):894-902.

34. Beard $J$, Hendricks MK, Perez EM, Murray-Kolb LE, Berg A, Vernon-Feagans L, Irlam J, Isaacs W, Sive A, Tomlinson M. Maternal iron deficiency anemia affects postpartum emotions and cognition. J Nutr. 2005;135(2):267-72.

35. Maes M, Van de Vyvere J, Vandoolaeghe E, Bril T, Demedts P, Wauters A, Neels $\mathrm{H}$. Alterations in iron metabolism and the erythron in major depression: further evidence for a chronic inflammatory process. J Affect Disord. 1996;40(1-2):23-33.

36. Schiepers OJ, Wichers MC, Maes M. Cytokines and major depression. Prog Neuro-Psychopharmacol Biol Psychiatry. 2005;29(2):201-17.

37. Maes M. Evidence for an immune response in major depression: a review and hypothesis. Prog Neuro-Psychopharmacol Biol Psychiatry. 1995;19(1):11-38.

38. Maes M, Song C, Lin A, De Jongh R, Van Gastel A, Kenis G, Bosmans E, De Meester I, Benoy I, Neels H, et al. The effects of psychological stress on humans: increased production of pro-inflammatory cytokines and Th1-like response in stress-induced anxiety. Cytokine. 1998;10(4):313-8.

39. Young JJ, Bruno D, Pomara N. A review of the relationship between proinflammatory cytokines and major depressive disorder. J Affect Disord. 2014;169:15-20.

40. Miller AH, Maletic $V$, Raison CL. Inflammation and its discontents: the role of cytokines in the pathophysiology of major depression. Biol Psychiatry. 2009; 65(9):732-41. 
41. Leonard BE. The concept of depression as a dysfunction of the immune system. Curr Immunol Rev. 2010;6(3):205-12.

42. Kim Y-K, Na K-S, Myint A-M, Leonard BE. The role of pro-inflammatory cytokines in neuroinflammation, neurogenesis and the neuroendocrine system in major depression. Prog Neuro-Psychopharmacol Biol Psychiatry. 2016;64:277-84.

43. Rybka J, Kędziora-Kornatowska K, Banaś-Leżańska P, Majsterek I, Carvalho LA, Cattaneo A, Anacker C, Kędziora J. Interplay between the pro-oxidant and antioxidant systems and proinflammatory cytokine levels, in relation to iron metabolism and the erythron in depression. Free Radic Biol Med. 2013;63:187-94.

44. Taraz M, Khatami M-R, Gharekhani A, Abdollahi A, Khalili H, Dashti-Khavidaki S. Relationship between a pro-and anti-inflammatory cytokine imbalance and depression in haemodialysis patients. Eur Cytokine Netw. 2012;23(4):179-86.

45. Jones I, Heron J, Blackmore ER, Craddock N. Incidence of hospitalization for postpartum psychotic and bipolar episodes. Arch Gen Psychiatry. 2008; 65(3):356.

46. Matthey S, Ross-Hamid C: The validity of DSM symptoms for depression and anxiety disorders during pregnancy. J Affect Disord. 2011;133(3):546-52.

47. Di Florio A, Meltzer-Brody S. Is postpartum depression a distinct disorder? Curr Psychiatry Rep. 2015;17(10):1-6.

48. Hoertel N, López S, Peyre H, Wall MM, González-Pinto A, Limosin F, Blanco C. Are symptom features of depression during pregnancy, the postpartum period and outside the Peripartum period distinct? Results from a nationally representative sample using item response theory (IRT). Depress Anxiety. 2015;32(2):129-40.

49. Giallo R, Gartland D, Woolhouse H, Brown S. Differentiating maternal fatigue and depressive symptoms at six months and four years post partum: considerations for assessment, diagnosis and intervention. Midwifery. 2015; 31(2):316-22.

50. NICE. Antenatal and postnatal mental health: clinical management and service guidance. 2015

51. Goodman JH, Tyer-Viola L. Detection, treatment, and referral of perinatal depression and anxiety by obstetrical providers. J Women's Health. 2010 19(3):477-90.

52. National Blood Authority. The national blood authority's patient blood management guideline: module 5 - obstetrics and maternity. 2015.

53. Beyondblue. Clinical practice guidelines for depression and related disorders anxiety, bipolar disorder and puerperal psychosis - in the perinatal period. A guideline for primary care health professionals. Melbourne: Beyondblue: The National Depression Initiative; 2011.

54. Khambalia AZ, Collins CE, Roberts CL, Morris JM, Powell KL, Tasevski V, Nassar N. Iron deficiency in early pregnancy using serum ferritin and soluble transferrin receptor concentrations are associated with pregnancy and birth outcomes. Eur J Clin Nutr. 2016;70(3):358-63.

55. Vliegen N, Casalin S, Luyten P. The course of postpartum depression: a review of longitudinal studies. Harv Rev Psychiatry. 2014;22(1):1-22.

\section{Ready to submit your research? Choose BMC and benefit from:}

- fast, convenient online submission

- thorough peer review by experienced researchers in your field

- rapid publication on acceptance

- support for research data, including large and complex data types

- gold Open Access which fosters wider collaboration and increased citations

- maximum visibility for your research: over $100 \mathrm{M}$ website views per year

At BMC, research is always in progress.

Learn more biomedcentral.com/submissions 